\title{
Harpalus (Baeticoharpalus) lopezi, new subgenus and new species of Harpalus from the Iberian Peninsula (Coleoptera, Carabidae: Harpalini)
}

\author{
José Serrano \& José Luís Lencina
}

Serrano, J. \& Lencina, J. L. 2008: Harpalus (Baeticoharpalus) lopezi, new subgenus and new species of Harpalus from the Iberian Peninsula (Coleoptera, Carabidae: Harpalini). - Entomol. Fennica 19: 193-198.

In this paper we describe the new subgenus Baeticoharpalus Serrano \& Lencina and a new species Harpalus (Baeticoharpalus) lopezi Serrano \& Lencina, based on a unique character combination that includes the pubescence of temples, frons, pronotum and elytra, the lack of mentum tooth, the shape of mouth parts and the male genitalia. The new taxon was collected in Sierra Morena (Pico de Almadén, central Betic Mountains, south Spain) and is geographically isolated from related taxa. Distribution data suggest that this is a relict species. The taxonomic position of the new taxon is discussed in relation to the other Iberian subgenera of Harpalus and the related genera Pangus, Pseudoophonus, Ophonus, etc. A key to Iberian Harpalus and related taxa is included; it illustrates the abundance of homoplasic characters within these taxa and the difficulties to develop a 'natural' key for identifying them.

J. Serrano \& J. L. Lencina, Department of Zoology and Physical Anthropology, University of Murcia, Facultad de Veterinaria, Campus de Espinardo, 30071 Murcia,Spain; E-mails: jserrano@um.es\&jllg@um.es

Received 15 February 2007, accepted 29 October 2007

\section{Introduction}

The genus Harpalus Latreille, 1802 is one of largest of the family Carabidae in species number. According to Noonan (1976) it includes 32 subgenera and about 480 species mostly in the Palearctic, Nearctic and Neotropical Regions; there are 60 Ethiopic species and a few ones in the Oriental Region. In the recent World list of Lorenz (2005), the genus includes fewer subgenera (10) and species (367), because some of the subgenera admitted by Noonan were ranked as genera. The genus shows a remarkable variability in external characters which explains the different criteria put forward by authors about its limits. Thus,
Noonan (1976) lumped most taxa related to Harpalus in a single genus, whereas Kataev et al. (2003) rised Ophonus Dejean, 1821, Pangus Dejean, 1821 and Typsiharpalus Tshitschérine, 1901 (among other taxa) to the genus rank. Other taxa such as Cryptophonus Brandmayr \& ZettoBrandmayr, 1982 and Pseudoophonus Motschulsky, 1844 are currently recognized as subgenera of Harpalus, except for authors following the Jeannel school.

The separation of Harpalus from related genera and the division of this genus into subgenera has not yet attained a general agreement. There is no World key for all these taxa, nor a Palearctic key of the subgenera of Harpalus. Important 
characters to differentiate Ophonus and related taxa from Harpalus and its allied groups were discussed by Brandmayr et al. (1980), including the type of clypeous teeth, the setae on the stipes and the supernumerary teeth of mandibles in the larvae, the dorsal vestiture, the pubescence of paraglossae and the aedeagus in the imagoes. These characters led Brandmayr et al. (1980) to distinguish an ophonoid lineage made up by all the subgenera of Ophonus and the Harpalus tenebrosus group (this last was ranked as the new subgenus Cryptophonus by Brandmayr and Zetto-Brandmayr in 1982), from the harpaloid lineage that includes Harpalus, Pseudoophonus, Pardileus, Acardystus, and Harpalophonus among other taxa. The analysis of these characters showed that apomorphies defining the ophonoid lineage are only found in the larvae, because key characters of the adult seem to be notably homoplasic as they have been developed independently in separate lineages of Harpalus and related taxa (Brandmayr et al. 1980). The molecular data reported by Martínez-Navarro et al. (2005) showed the isolation of Ophonus from the Harpalus-related taxa, the affinity between $\mathrm{Pseu}$ doophonus and Harpalus and the equivocal position of Cryptophonus.

When attempting to identify five individuals of a hairy Harpalus species collected in Sierra Magina (central Betic Mountains, south Spain), it was clear that they corresponded to a new species. Further, the combination of external characters did not match those of currently accepted subgenera existing in the western Palearctic region, and thus the new species possibly represented an unknown lineage deserving the subgenus rank. These preliminary findings were quite surprising because the genus Harpalus is well known in the Iberian Peninsula, and the Betic Mountains have been reasonably sampled in the last decades. This paper describes the new species, discusses the erection of a new subgenus of Harpalus and formulates a number of hypotheses about the new species to be verified in future studies, including larval and molecular analyses. A key to Iberian Harpalus and related taxa is included to reflect the problems derived from the usage of homoplasic characters in the lineage of Harpalus sensu lato, and to help in evaluating the systematic position of the new species.

\section{Baeticoharpalus subg. $\mathbf{n}$.}

Type species: Harpalus (Baeticoharpalus) lopezi Serrano \& Lencina, sp. n., by monotypy

Diagnosis. Black, shiny, without dorsal microsculpture. Size around $9 \mathrm{~mm}$. Wingless. Antennae infuscate except for the pale red first antennomere, and reaching the elytral basis. Palpi pale red. Short pubescence present in temple (some isolated setae are also found in the frons), sides and margins of pronotum, and in all elytral intervals. Pronotum transverse, slightly sinuate before the posterior angles, that are obtuse but well marked. Scutellar stria present of average length. Humeri evident with a small tooth. Elytra slightly sinuate before apex. Femora and tibiae almost black, tarsi paler, pro- and mesotarsi of males dilated. Tarsi glabrous above except for the normal apical setae. Paraglossae pubescent, first labial palpomere without diagonal carina, ligula with two apical setae, mentum without tooth. Submentum, prosternum, proepisternae and propleura with short pubescence, mesosternum glabrous and almost impunctate. Metaepisternae longer than wider ( $\mathrm{L} / \mathrm{W}=1.2-1.4)$, moderately punctate and pubescent. Metasternum glabrous except for 1-2 isolated setae. Last ventral sternites pubescent at each side of median line. Median lobe of aedeagus average for the genus, with a straight apex moderately dilated and discrete apical disk; the sclerites (two teeth, one field of microtrichia and another of macrotrichia) are also average for the genus.

Specific epithet. The new subgenus is named according to the location of the type locality in the Betic sierras.

Remarks. The new subgenus shows a number of affinities to other Harpalus, as are the general form and size, the details of mouth parts (pubescence of paraglossae, labial palpi), and the type of aedeagus. However, the pubescence of temples and frons combined with the lack of mentum tooth are not found in subgenera of Harpalus. The new subgenus is geographically isolated as no other species of the west Palearctic Region shows these features. However, its relationships should be further investigated by analyzing Harpalus taxa from Asia, where the genus is much diversified (see Kataev 1987, 1991, 2001 and further references therein). In particular, it 
becomes clear that dorsal vestiture, including the temples and the frons, is a homoplasic character not suitable for phylogenetic analyses in Harpalus and related taxa. Likewise, the diagonal carina of the first labial palpomere is also homoplasic as it is found in both the ophonoid (all members) and the harpaloid (Pseudoophonus) lineages. This compels to elaborate key to adults based on combinations of multiple characters instead of using apomorphies (see the key below).

It is hypothesized that larvae of Baeticoharpalus will show the clypeus, the stipes and the mandibular teeth proper of the harpaloid lineage described by Brandmayr et al. (1980). Likewise, a molecular analysis will show that Baeticoharpalus will appear in a clade close to Harpalus and Pseudoophonus and separate from Ophonus and Cryptophonus.

\section{Harpalus (Baeticoharpalus) lopezi Serrano \& Lencina, sp. $n$.}

Type material. Holotype male labeled with a white card: "Pico Almadén, 2,097 m. Mancha Real, Jaén. 16.4.2005. M. López leg.”, and a red label indicating HOLOTYPE. The male genitalia is mounted in a transparent plastic card on the same pin.

Paratypes: two males and two females labeled with a white card stating "Hispania. Torres (J). Sierra Mágina, Pico El Almadén. 2,032 m. 1-V2006. Lencina, Baena, López, Bujalance \& Castro leg.", and a red label stating PARATYPE. The male genitalia of both males are mounted in a transparent plastic card on their respective pin.

The holotype and two paratypes are deposited in the collection of the Department of Zoology of the University of Murcia. The other paratypes are deposited in the collection of José Luís Lencina.

Description. Habitus as in Fig. 1. Length 9.0 mm (holotype), 9.7-8.0 mm (paratypes). Body relatively slender, shiny black without dorsal microsculpture. First antennomere pale reed, second infuscated, 3-11 piceous but slightly paler to apex. Palpi pale reed. Legs black with tarsi pale red (pro- and mesotarsi) or piceous (metatarsi). Wingless.

Head. Anterior margin of labrum almost stright, not arcuate. Anterior margin of epistome

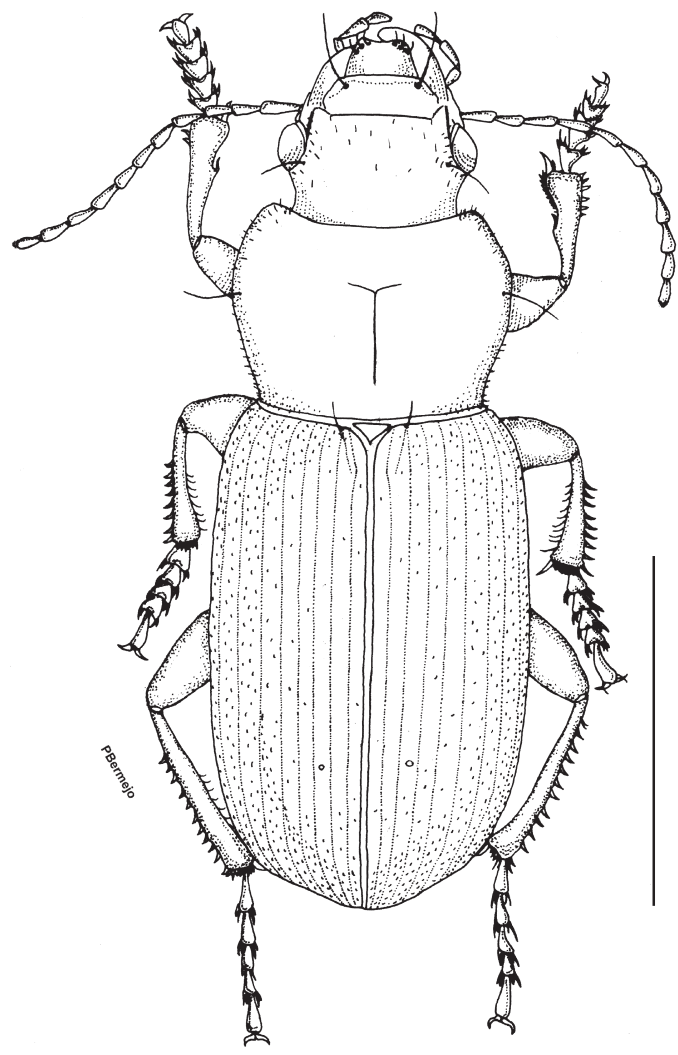

Fig. 1. Habitus of Harpalus (Baetiocharpalus) lopezi $\mathrm{sp}$. $\mathrm{n}$. The bar equals $5 \mathrm{~mm}$.

very slightly arcuate. Frons with indistinct clypeo-ocular furrows. Eyes moderately protruding, neck normally strechted. Temples pubescent, the pubescence is also present in the supraorbital grooves, isolated setigerous punctures are also found in the epistome and the frons. Paraglossae pubescent, ligular sclerite narrow, with two long ventro-apical setae, first labial palpomere without the diagonal carina present in Ophonus. Mentum without median tooth, sides not thickened, submentum with short pubescence (Fig. 2).

Pronotum. Disk flattened. Anterior margin beaded only close to angles, posterior margin entirely beaded. Anterior basis regularly arcuate, angles moderately protruding. Posterior angles obtuse, well-developed. Sides moderately sinuate before hind angles. Basal impression vaguely indicated with some coarse punctures. Sides pubescent, the pubescence extended on the anterior angles and on the posterior basis up to to the basal impression. 


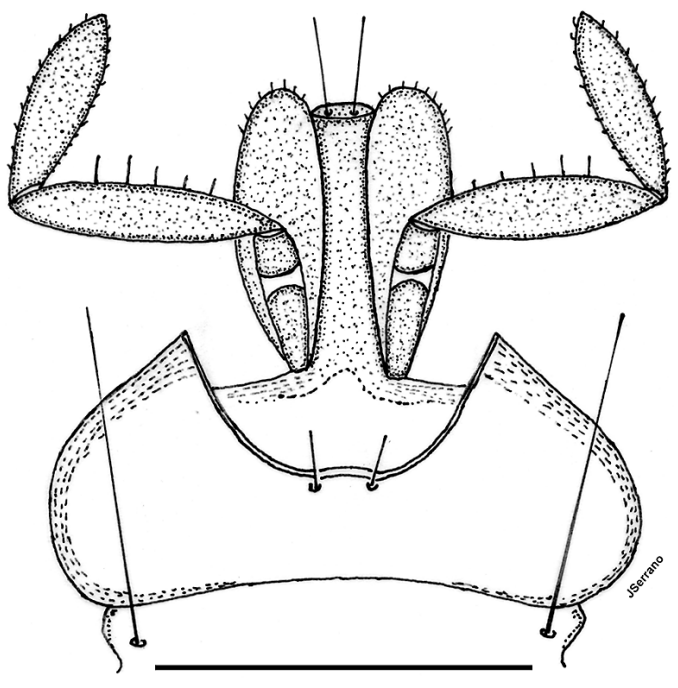

Fig. 2. Details of bucal parts of $H$. (B.) lopezi sp. n. The bar equals $1 \mathrm{~mm}$.

Elytra. Relatively slender and almost parallelsided, slightly sinuate before apex. Humeral tooth present. Disk flattened, intervals almost flat, striae well marked but impunctate. Scutellar stria with basal setigerous puncture. Normal setigerous puncture in the last third of the third stria or the third interval. Pubescence well developed in intervals 6-9, almost absent in intervals $1-5$, but dense on the beginning and the apex of all intervals.

Thorax (ventral sclerites) and abdomen. Prosternum pubescent, propleura sparsely punctate. Metaepisternae longer than wider (L/W $=1.2$ 1.4) with sparse punctures and pubescence. Metacoxa with few isolated punctures. Last abdominal sternites pubescent with long hairs at each side of median line.

Antennae and legs. Antennae of average size for Harpalus, reaching the beginning of elytra, with pubescence from the $2 / 3$ of the third antennomere. The first antennomere has an extra subterminal seta before the long apical seta. Proand mesotarsi of males clearly dilated with ventral biseriate adhesive vestiture. All tarsomeres lack the dorsal pubescence existing in Ophonus. Protibiae with 3-4 small spines in the outer distal apex. First metatarsum shorter than second plus third.

Male genitalia. Median lobe of aedeagus with the typical shape of Harpalus (Fig. 3a), the apex

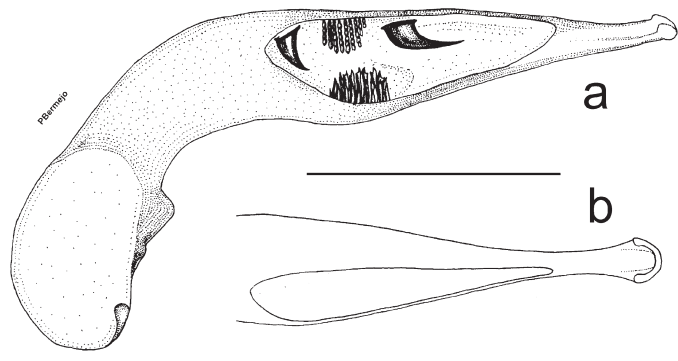

Fig. 3. Male genitalia of $H$. (B.) lopezi sp. n. - a. Median lobe of aedeagus. $-b$. Details of the apex in dorsal view. The bar equals $1 \mathrm{~mm}$.

is well developed and is almost straight, moderately widened towards tip and without ventral serrate shaft (Fig. 3b). Endophallus with two large teeth, one medial, other apical, a basal field of macrotrichia and a more distal and dorsal field of microtrichia (Fig. 3a).

Specific epithet. The species is named after Marcos López, who kindly offered us the first individual of the new subgenus and species.

Geographic distribution. The species is solely known from the type locality, the peak of Almadén, located in Sierra Mágina (province of Jaén, Andalusia, south Spain), coordinates 37.734421 (latitude), -3.523874 (longitude).

Habitat. The five individuals of the new species were collected under stones in the meadows surrounding the Almadén Peak (Fig. 4), between 1,950 and 2,023 $\mathrm{m}$ of altitude. The vegetation corresponds to the associations that dominate the Supramediterranean and Oromediterranean belts of the Betic Mountains, including the Sierra Nevada (Mota et al. 2002). Common plants of the area include Erinacea anthyllis, Berberis hispanica, Prunus ramburii, Phlomis crinita, Genista versicolor, Thymus serpylloides, Juniperus communis ssp nana, Hormathophyla spinosum and Sideritis glacialis.

The carabid assemblage of the area is proper of stony places located in meadows at high altitudes of Betic sierras. Collected species were Leistus spinibarbis (Fabricius 1775), Notiophilus biguttatus (Fabricius 1779), Calathus baeticus mateui Nègre, 1969, Zabrus ambiguus Rambur, 1837, Carterus fulvipes Latreille, 1817, Harpalus honestus (Duftschmid, 1812), H. sulphuripes goudotii Dejean, 1829, H. wagneri Schauberger, 1926, H. serripes (Quensel 1806), Ophonus azu- 
Fig. 4. A view of the type locality of $H$. (B.) lopezi sp. n., the Almaden Peak in Sierra Mágina (province of Jaen, south Spain).

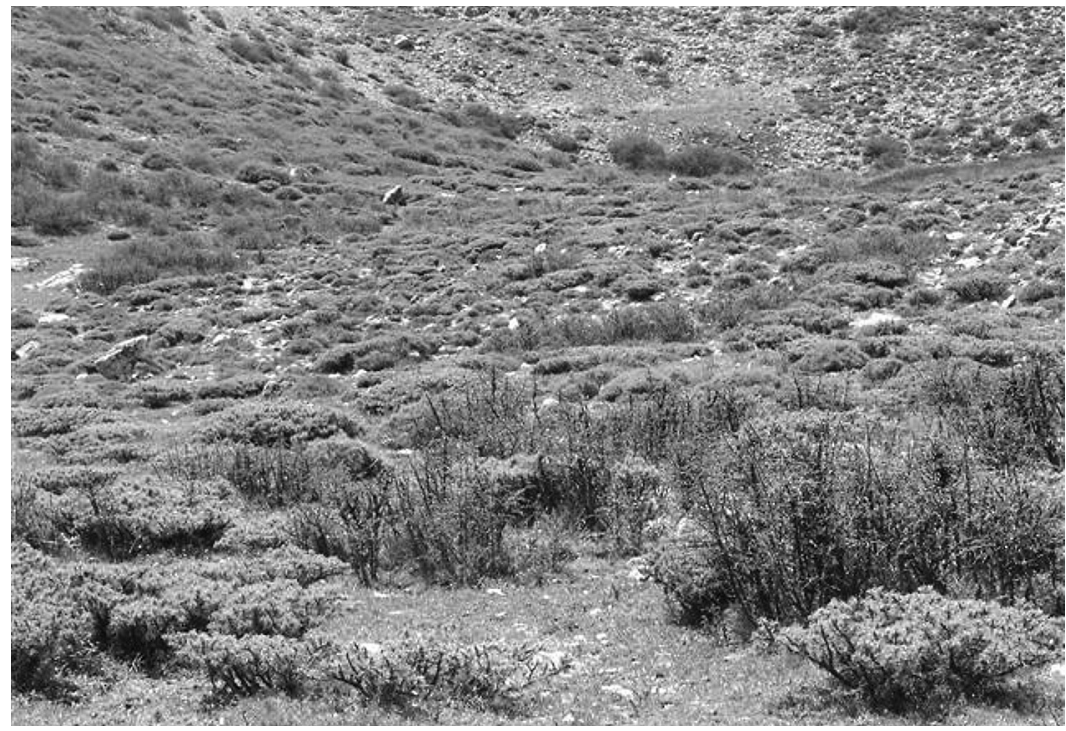

reus (Fabricius, 1775), Trymosternus cordatus Rambur, 1837, Cymindis etrusca baetica Rambur, 1837, C. lineola (Duftschmid, 1812), Microlestes abeillei (Brisout de Barneville, 1885), Philorhizus crucifer Lucas, 1846 and Brachinus pateri Puel, 1938. The new species possibly exists in the whole Supramediterranean belt but further sampling is needed to determine its altitudinal range.

Remarks. Adults of Harpalus (Baeticoharpalus) lopezi are easily recognized from related species of Harpalus, particularly from the Iberian Peninsula, because of the unique combination of pubescence and mouth characters (see the key below). The origin of the new species is uncertain. On morphological grounds there are no close relatives among the Iberian Harpalus. Further, its occurrence in the central part of the Betic Mountains does not support any clue on biogeographical grounds. These mountains (that include Sierra Mágina) are poor in endemic species. There are three hypogean taxa (belonging to the genera or subgenera Typhloreicheia Holdhaus, 1924, Geocharis Ehlers, 1883 and Typhlocharis Dieck, 1869) and two epigean (Tinautius Mateu, 1997 and Laemostenus, Bonelli, 1810). This fact is explained because the central Betic Mountains are a transitional area between the northern carabid fauna coming from Europe and the Sierra Nevada (Serrano et al. 2003). There are few peaks surpassing $2,000 \mathrm{~m}$ in altitude in the central Betic Mountains. This makes speciation of cold-adapted taxa difficult during the xeric interglacial periods. It therefore seems more reasonable to hypothesise that Sierra Mágina is a relict locality of a formerly wider distribution area of $H$. lopezi . It is expected that a molecular analysis may help in unravelling its evolutionary history.

\section{Key to Harpalus and related supraspecific taxa of the Iberian Peninsula}

1. Paraglossae glabrous (one or two isolated setae may be found in Cryptophonus). First labial palpomere with a diagonal carina. 2

- Paraglossae pubescent, at least with 4-6 short lateral setae close to apex. First labial palpomere without a diagonal carina except for Pseudoophonus.

2. Temple pubescent. Elytra uniformly punctate or pubescent at least in the external intervals.

- Temple glabrous. Elytra glabrous except for the normal setigerous puncture of the third interval; a small row of punctures may be found apicad in the seventh (and occasionally the fifth) interval, or in the eighth interval.

genus Cryptophonus

3. Elytra with uniform dorsal pubescence. Metatarsi with dorsal pubescence (it is absent 
in rare species). Metacoxae with short and dense pubescence. genus Ophonus

- Elytra with dorsal pubescence limited to the outer intervals, the anterior basis and the apex. Metatarsi without dorsal pubescence, only a few, short and apical setae may be present. Metacoxae with large but sparse setae.

genus Typsiharpalus

4. First labial palpomere with a diagonal carina. Metatarsi pubescent. genus Pseudoophonus

- First labial palpomere without a diagonal carina. Metatarsi glabrous.

\section{5}

5. Prothorax with long, erect setae anteriorly. Mentum without median tooth.

genus Pangus

- Prothorax without long, erect setae anteriorly. Mentum often with a median tooth.

6. genus Harpalus

6. Dorsal pubescence of elytra uniform. Habitus Ophonus-like. subgenus Semiophonus

- Elytra glabrous or with short uniform pubescence limited to outer intervals and irregular sparser punctures in inner intervals. Habitus Harpalus-like.

7. Temple, frons, sides of pronotum and outer intervals (6-8) of elytra pubescent. Mentum without median tooth $(H$. dispar has frons but not temple pubescence, sides of pronotum are not sinuate before hind angles and has mentum tooth). subgenus Baeticoharpalus

- Temple glabrous, frons also glabrous except for $H$. dispar, only sides of pronotum and outer intervals of elytra may be pubescent. Mentum with or without median tooth. 8

8. Scutellar stria rudimentary and poorly delimited. Elytra flattened with pubescence in all intervals but sparser and irregular in inner ones. Mentum without median tooth.

subgenus Licinoderus

- Scutellar stria well developed. Elytra variable, from flattened to convex, pubescence, when present, limited to outer intervals (except in $H$. dispar). Mentum usually with well developed median tooth.

9. Sides of pronotum with a single large seta close to or just in the middle.

subgenus Harpalus

- Sides of pronotum with 6-8 long setae (though shorter than the normal seta in the middle), but easily lost in $H$. dispar (in that case the frons is pubescent).

subgenus Artabas

Acknowledgements. Thanks are due to Marcos López for offering us the first individuals of the new species and to Manuel Baena, José Luís Bujalance and Alejandro Castro who also collaborated in collecting more individuals of this species. Patricia Bermejo Gómez much helped with the drawings. This work has been supported by project 00595/PI/04, of the Fundación Seneca, Consejería de Educación de Murcia.

\section{References}

Brandmayr, P., Ferrero, E. \& Zetto-Brandmayr, T. 1980: Larval versus imaginal taxonomy and the systematic status of the ground beetle taxa Harpalus and Ophonus (Coleoptera: Carabidae, Harpalini). — Entomol. Gen. $6(2 / 4): 335-353$.

Brandmayr, P. \& Zetto-Brandmayr, T. 1982: Identificazione di larve del genere Ophonus Dejean, 1821 (sensu novo) e note bionomiche (Coleoptera, Carabidae). - Mem. Soc. Entomol. Ital. 60: 67-103.

Kataev, B. M. 1987: (Ground-beetles of the genus Harpalus Latr., group affinis). — Tr. Zool. Inst. Akad. Nauk. SSSR 170: 3-41.

Kataev, B. M. 1991: (A new species of the genus Harpalus of the "anxius" species group (Coleoptera, Carabidae) from Asia Minor). - Akad. Nauk. URSS Zool. 9: 147-149.

Kataev, B. M. 2001: Revision of the Harpalus honestus group from the Himalaya and a review of the Harpalus species from Nepal (Coleoptera: Carabidae). — Russian Entomol. J. 10 (4): 357-384.

Kataev, B. M., Wrase, D. W. \& Ito, N. 2003: Subtribe Harpalina Bonelli, 1810. — In: Löbl, I. \& Smetana, A. (eds.), Catalogue of Palaearctic Coleoptera. Vol. 1 Archostemata, Myxophaga, Adephaga: 367-397. Apollo Books, Stenstrup.

Lorenz, W. 2005: Systematic list of extant ground beetles of the World. $530 \mathrm{pp}$. - Tutzing, edited by the author.

Martínez-Navarro, E. M., Galián, J. \& Serrano, J. 2005: Phylogeny and molecular evolution of the tribe Harpalini (Coleoptera, Carabidae). inferred from mitochondrial cytochrome-oxidase I. - Mol. Phyl. Evo1. 35: 127-146.

Mota, J. F., Pérez-García, F. J., Jiménez, M. L., Amate, J. J. \& Peñas, J. 2002: Phytogeographical relationships among high mountain areas in the Baetic Ranges (South Spain). — Global Ecol. Biogeogr. 11: 497504.

Noonan, G. R. 1976: Synopsis of the supra-specific taxa of the tribe Harpalini (Coleoptera: Carabidae). Quaest. Entomol. 12: 3-87.

Serrano, J., Lencina, J. L., \& Andújar, A. 2003: Distribution patterns of Iberian Carabidae (Insecta, Coleoptera). - Graellsia 59: 129-153. 